Portland State University

PDXScholar

7-31-2017

\title{
Language Shift \& Language Maintenance Among Farsi Speakers in Portland, Oregon
}

Clarissa Gaillardet

Portland State University

Follow this and additional works at: https://pdxscholar.library.pdx.edu/honorstheses Let us know how access to this document benefits you.

\section{Recommended Citation}

Gaillardet, Clarissa, "Language Shift \& Language Maintenance Among Farsi Speakers in Portland, Oregon" (2017). University Honors Theses. Paper 470.

https://doi.org/10.15760/honors.470

This Thesis is brought to you for free and open access. It has been accepted for inclusion in University Honors Theses by an authorized administrator of PDXScholar. Please contact us if we can make this document more accessible: pdxscholar@pdx.edu. 
Language Shift \& Language Maintenance Among Farsi Speakers in Portland, Oregon

\author{
by \\ Clarissa Gaillardet
}

An undergraduate honors thesis submitted in partial fulfillment of the requirements for the degree of

Bachelor of Arts

in

University Honors

and

Applied Linguistics and German

Thesis Adviser

Dr. Tucker Childs

Portland State University 


\section{Table of Contents}

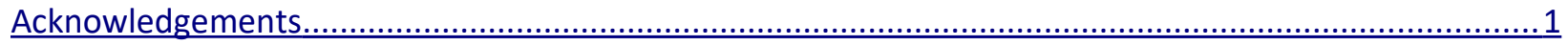

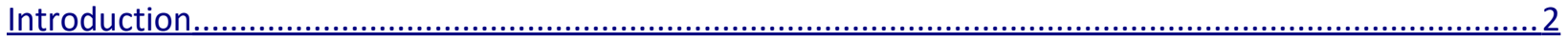

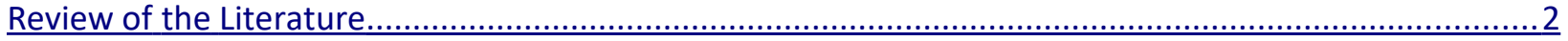

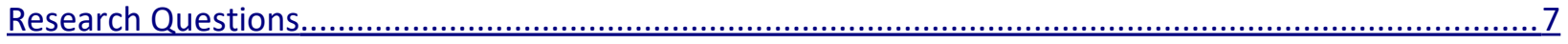

Methodology

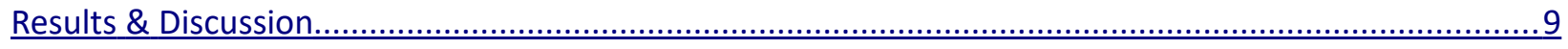

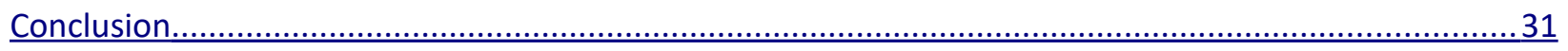

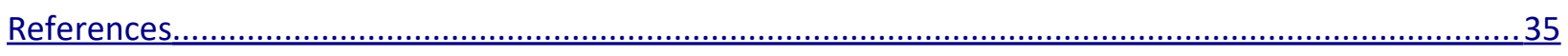

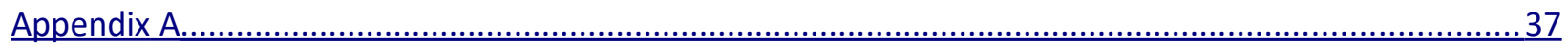

Appendix B 


\section{Acknowledgements}

Every novice researcher stands on the shoulders of giants to reach as high as they have, and I am no exception. Here are my giants: Dr. Anousha Sedighi, who provided me with the resources I needed to access the community of scholars whose discourse focuses on Persian linguistics and the Persian diaspora; Dr. Tucker Childs, who guided me every step of the way, providing me with everything I needed to write a thesis from start to finish, who revised my drafts constantly and fielded any and every possible question I had; the Halsell-Vore family, for listening to my complaints with patience and insight, and providing me with food, company, and moral support whenever I was in need; my research participants, to whom I extend my deepest gratitude -- without them, I would have had to create an entirely different thesis. Thank you for meeting me, spending your time with me, and sharing important parts of your lives with me and with yourselves. And to you, reader, for lending your time and energy to my work. May you learn from my insights and forgive my mistakes. 


\section{Introduction}

Human interactions have changed dramatically in recent times, especially with increased mobility and new social structures. Language, of course, is central to those interactions and has itself changed to reinforce and strengthen, or resist, those structures. Nationalities and borders have developed, with arbitrary lines between groups of people, splitting groups of people and introducing new identities. The conflicting forces of growing nationalism and increasing globalization have contributed to increasing cultural and language contact. When different peoples and their languages occupy the same space, a new language economy emerges, one consequent of which is language shift, when the speakers of one language abandon it in favor of another language. If, however, the original language of the group is kept, language maintenance occurs. Although the trend towards language shift is not universal, it is the more common of the two phenomena.

\section{Review of the Literature}

In immigrant communities, language shift usually occurs in such a way that by the third generation, speakers are commonly fluent in the language of the surrounding linguistic group, with little to no use of their family's heritage language (Romaine, 2000). However, language shift can occur more gradually when factors arise that encourage language maintenance, and certain communities may successfully retain their language over the course of multiple generations.

The United States presents numerous cases of complex and evolving bilingualism ${ }^{1}$. Although the US has a great number of languages and a remarkable variety of types of mono- and multilingualism, it is often the case that this multilingualism is unstable. Many immigrants arrive in the US, only to have bilingualism quickly disappear in their communities, i.e., to experience language shift. Bilingualism is thus often a state of transition for many speakers. Tse (2001b)

\footnotetext{
${ }^{1}$ Although the term "bilingualism" is used here, many situations of language contact feature trilingualism or even multilingualism involving three or more languages.
} 
describes the process of the three- generation lifespan of US bilingualism:

An adult immigrant arrives in the United States and learns enough English to operate in daily life, while continuing to use her stronger tongue-the heritage language-at home. She raises her children to speak the heritage language, but as these children enter school and learn English, they switch to English when speaking with their siblings and friends. By the time they graduate from elementary school, these same children are better speakers of English than they are of the home language and prefer using English in nearly every realm. When they grow up and have children of their own, English is typically the only language spoken in their own home, and these grandchildren have little to no familiarity with the heritage language (pp. 30-31).

Identifying the reasons behind language shift is the question faced here. Pressures from language policy movements such as the English-only movement (Crawford, 1992) combine with pre-existing socio-economic pressures to promote the shift from heritage languages to the majority language in the United States. Many studies have looked at socio-economic factors that pressure minority communities into gradually abandoning their heritage language. Desires to fit in and achieve academic and financial success certainly come into play. However, changes at the macro-socioeconomic level are not as telling as language change at the micro levelultimately, it is the individual who must make the choice of which language(s) to use, according to scholars such as Tse (2001a), who believe that understanding what is influencing the individual will help contribute towards efforts to stem community-level language shift. Particularly for the second generation of immigrant families, "personal factors that may influence an individual child to develop or neglect his or her heritage language" (p. 103) have been neglected in studies of language shift (Shin, 2002). This study will focus on just those personal factors.

Previous scholarship on language shift in the United States has tended to look at minority groups that are large or have been in the United States for a long period of time. In contrast, this study will examine a smaller group, speakers of Persian or Farsi (the terms will be used here interchangeably), who have emigrated from Iran. Research on the Persian diaspora 
has begun to look into this community primarily through qualitative data such as surveys, interviews, and observation of childrearing environments. One such study is the work of Shiraz Felling (2006), an important study in that literature, that the current study is deeply indebted to. First I consider other current scholarship on language shift in Farsi, and then look in detail at that work and explain how it has influenced this study.

One early study of language shift in the Iranian diaspora highlighted the importance of studying Iranian communities and called for further research on the second generation of Iranian immigrant families in order to gauge patterns of assimilation (Bozorgmehr, 1998). It was found that in concentrated Iranian populations, such as in California, a higher percentage of respondents than in less concentrated communities identified with their Iranian ethnicity. Concern for potential community fragmentation was voiced, due to the second generation leaning towards ethno-religious identification rather than an Iranian sense of belonging. Younger participants would identify as Muslim or agnostic before identifying as Iranian. Bozorgmehr also voiced concerns over the small communities not being able to withstand the influences of mainstream American culture. The current study is also concerned with the population size of the diaspora and how it affects the individual's sense of identity. Bozorgmehr's work serves as a reference point for how questions of identity can be influenced by the sense of community that a research participant feels.

A more recent study looked at the effects of a community-based Persian language school in a southern U.S. city (Shirazi, 2014). This work examined the effects of the Persian school on local Persian families and the sense of cultural learning they could pass on to the next generation. The school featured instruction in kindergarten through fifth grade for two hours per week. The politically and religiously neutral community center helped combat the sense of "Othering" that children were receiving from peers and helped to affirm their connections to the Iranian culture as a normal, positive part of their identities. The act of passing on the family language to the youth in the community was able to bring together families of Iranian descent with diverse religious and ideological backgrounds, strengthening 
familial bonds for parents and allowing children an outlet to combat the negative input they received from peers at school. One participant in the current study also felt a sense of othering, and for a period of time in high school, did not feel that she had the resources to fight the peer pressure that faced her, yet she persisted in reclaiming her language and culture.

A 2008 study used domain analysis to analyze Farsi and Swedish language use inside and outside the home in Sweden. Interestingly, the subject matter being discussed became a significant factor in the study, as conversations in the home were dominated by Farsi, with the exception of school topics (Namei, 2008). Outside the home, Swedish was preferred, even by mothers, who tended to speak more Swedish than fathers due to being more directly involved in the education of their children. Members of the second generation of Iranian immigrant families tended to use Swedish frequently among themselves, despite using Farsi with parents and older members of the community. Because of these findings, the home domain and domains outside the home are considered relevant factors to the analysis here.

Another important study focused on second-generation Iranian immigrants' sense of identity, and found that participants reported a "mixed" sense of identity (Mahdi, 1998). There was a strong desire to preserve the heritage culture, as well as a willingness to assimilate into the greater "American" culture. Because of the high mobility and diverse occupations of the community, Iranians lived far apart; this spread precluded frequent social interaction with other Iranian families. Because of this lack of consistent socialization in a community with an Iranian identity and Persian-language use, Mahdi suggested that efforts to pass on the language and culture to current and future youth would need to become more purposeful and concentrated. Mahdi's study shows a trend, similar to the current study, of suggesting that efforts to revitalize Farsi will need to be more formalized in the future than they have been in the past.

The hostility of other Americans towards Iranian-Americans also played a role in respondents' sense of identity. However, this hostility was experienced only occasionally, 
typically as verbal attacks on individuals. More commonly, Iranian youth described their experience as a struggle to see their own culture without the lens of the American idea of what it means to be Iranian (Mahdi, 1998). Because of this reported struggle, participants in the current study were also asked about how identity played a role in their language use.

Another study looked at language maintenance for one Iranian-Canadian who maintained his Farsi despite living in England for four years as a child (Babaee, 2013). His parents' insistence that he speak Farsi during their sojourn in England, as well as his childhood tendency to seek acceptance and support from family members, aided the development and retention of his heritage language. Moreover, his family took him to visit Iran every summer during his four years abroad, and the small Iranian community in southern England also contributed to the Iranian-Canadian respondent's motivation to maintain his fluency in Farsi throughout childhood. This study serves as an example of how individual interest can be a strong motivator of language maintenance, along with other factors such as familial encouragement. This type of motivation is also evident in the current study, as some participants found internal motivation to practice their heritage language and were similarly supported by family members.

Research on factors that influence language shift often looks at demographic factors or major socioeconomic factors, i.e., as represented in census data. However, the family unit is where these decisions of shift and maintenance begin. Parents and older relatives make decisions concerning the language environment the younger generation will be exposed to. Likewise, the younger generations may choose to accept or defy language norms established within their families. This paper therefore focuses on a study of how pressures from within the family affect language choice following Shiraz Felling (2006), who studied language shift in a Farsi-speaking community in Washington, D.C. She documented the successes and failures of parents to pass Farsi down to their children, and whether Farsi was retained within the family sphere. Felling conducted interviews with twenty-three Iranian-American parents, gathering personal accounts 
of the ideology and values associated with Farsi and English, and whether or not these concepts were realized in the daily life of the surveyed families. Interviews showed that although many parents believed that bilingualism was a positive factor in growth of their children and that passing Farsi on to their children will make them successful parents, the stress of everyday communication and the complicated realities of family life made carrying out these goals incredibly challenging. Previous studies had looked only at the multiple factors outside the home which influence language shift. Felling's study sought to fill a gap by analyzing factors within the home and family unit. The results of her study led to the hypothesis that in several generations, the shift will be complete: Farsi will be completely absent from the language of the youngest generation.

\section{Research Questions}

Based on this review of the literature, the following questions guide this study:

1. What is the status of Farsi in Portland, Oregon?

a. Is language shift occurring? Is there maintenance of Farsi?

b. When, where, and with whom are these languages spoken?

2. What guides language choice? Why do people choose to use one language rather than the other? What factors do individuals feel are motivating them to speak Farsi or English?

a. Do individuals feel pressures from family or society?

b. How are language use and cultural identity connected?

c. What resources exist for individuals to use?

d. What are individual's predictions for the future of their language? 


\section{Methodology}

The data for this study come from informal interviews with members of Iranian-American families. Some individuals were from the second generation, the children of immigrants, and some were first-generation immigrants. Most families came to the United States in the 1980's due to the Iranian Revolution, which began in 1978. The second-generation interviewees were born in the United States, and at the time of the study, were between the ages of 15 and 30. Other interviewees were first generation immigrants, and had raised this younger generation themselves, or interacted with them in a significant way. Participants were recruited through personal contacts, including friends, and professors at Portland State University.

Language ideology was the primary focus of the interviews, where language and cultural values were discussed explicitly and in context. Such talk about language was felt to be best obtained in interviews, which unlike surveys or questionnaires, provided optimal flexibility for guiding the responses of the participant. Participant responses for each individual interview thus led to unanticipated sub-questions and impromptu topic generation. Other methods provide a broad perspective on a language community, and generalizations can be made. However, the interviews used in this study allow for depth of perspective and exploration of each individual's experience. Additionally, gathering perspectives from both the first and second generation of immigrant families provided a multi-faceted look into the community not often found in other literature in the field of language shift.

Interviews took place in the homes of participants and in cafes or coffee shops. The length of individual interviews varied, but lasted generally from thirty to ninety minutes. The participants were made aware that the interviews would be recorded and that their identities would not be disclosed. The style of interviews was more of a friendly conversation than a structured interview, following the pattern of the "ethnographic interview," where the conversation slowly moved onto new topics that loosely guided the interviewee into 
responding on selected issues (Spradley, 1979).

Interviews generally started with questions about how many and which family members interacted with the interviewee, when these family members and the interviewee themselves came from Iran to Portland, Oregon, and which language(s) the interviewee spoke with whom and why. Topics included language use with specific family members as well as the reasoning behind why a particular language was spoken with each interlocutor (see Appendix B for questionnaire).

The interviews moved on to similar discussions of language use and the motivations behind them in work and school and in the community. Questions were also asked about any external pressures the individual may have felt to speak or act in certain ways, and if any technologies or materials were successful in helping them practice their heritage language or feel more connected to their heritage culture.

Data from each interview was analyzed first casually as each interview was concluded. After notes were made on each interview, analysis focused on the motivations behind language choices, ideologies about language and culture, and the language resources (or lack thereof) that the participants accessed. Interviews were then partially transcribed as relevant to include in this discussion. Analyzing interviews in this cyclical way allowed each successive interview to be more targeted and adapted to the individual as well as the emergent research questions.

\section{Results \& Discussion}

Out of the five participants interviewed, two were second-generation immigrants, having been born outside of Iran, with parents who moved to the United States in adulthood. Three participants were first-generation immigrants. To protect their anonymity, the participants will henceforth be referenced with relatively transparent codes to simplify their identification. The second-generation women will be labeled W1G2 and W2G2, while the first-generation men will be M1G1 and M2G1. The first-generation woman will be W1G1. A reference sheet in Appendix 
A is provided to aid correlation of speaker codes with the basic characteristics of each speaker. M1G1 moved from Iran to the United States as an adult, and has raised one child while living in Portland, Oregon. M2G1 also moved to Portland as an adult, and along with his Iranian wife, raised two children there. Within the immediate family of the W1G2 and W2G2, both their mother and father spoke Farsi and English. M1G1 was married to a non-Iranian native English speaker who spoke Farsi fluently. M2G1 married a Persian woman while in Canada and they raised two children while they lived together in Canada and the United States. W1G1, also a first-generation immigrant, came to Oregon from Iran with her mother. Although she was unmarried and had no children at the time of the present study, she had interactions with second-generation Persian-Americans in her family. Thus, in all four home environments with children, Farsi was spoken at fairly high fluency by both parents.

W1G2 had one older sibling, a mother, and a father in her immediate family. She was in her early twenties, and her brother, in his thirties. Although both her parents spoke both Farsi and English, they also spoke Assyrian with each other, as it was one of her mother's native languages. She was raised speaking Assyrian and Farsi, with English introduced later, around the age when her formal education began. “They didn't have to push it [English], because I was organically starting to speak English more and more." The school system added a language to her life that would not have been introduced so prominently otherwise. Like many other second generation children, this beginning of her school years was when W1G2 became vulnerable to possible language shift. W1G2 reported that her parents rarely spoke English with each other, choosing either Farsi or Assyrian the majority of the time because their fluency in these languages was greater than it was in English. While speaking with her parents, who used Farsi with her, she would often reply in English.

When I was in school, especially like, you know, $\mathrm{K}$ through -- not 12 , but like younger. $\mathrm{K}$ through middle school or something like that, I think my parents were not really trying to push me to speak Farsi or anything because they just wanted me to do good in school. 
Even though her parents spoke some Farsi with her at home, they did not actively encourage her to use Farsi during her school years. Being practical, they prioritized having their daughter feel comfortable as a "normal American" student, and did not consciously try to preserve their heritage language with her.

Once W1G2 entered high school, she began to lose contact with her extended family and family friends, people she had often spoken Farsi with. "When we were with family friends, that was when I was like, 'Oh, I should make sure I still know how to talk [Farsi]' or it's embarrassing." As she grew up, W1G2 gradually became more aware that some interlocutors in her life preferred or needed to use Farsi. Because of get-togethers with family friends, she realized that her language skills would need upkeep if she was to remain in good social standing. Throughout her childhood, she had been slowly paying less attention to her heritage language. At the time of the interview, this behavior had been changing for the preceding few years. When asked why she changed to more actively maintaining her Farsi, she replied, "to feel like I'm respecting that part of me, and using it enough where I won't forget it." W1G2 had recently begun Persian classes at a local university. These classes not only helped her develop literacy in the Persian script, but encouraged her to practice her heritage language more often with her family. Because of these classes, the default with her parents had become Farsi, with some English still present.

However, with her brother, conversations remained almost entirely in English, despite his stronger command of Farsi. The two siblings would switch to Farsi for just one word or phrase when they told jokes and when they wanted to speak secretly in front of others. W1G2 felt that even though their parents moved when he was just a one-year-old, her brother used little Farsi with her because his foreign birth may have caused the need to feel more "fully American." When her parents and her brother would conversate without her, she could hear them using much more Farsi, as well as Assyrian. She wondered if this was because her language skills were not as strong as theirs. There difference was sharp between how her father 
talked to her and how he talked to her brother. Her brother and father would often joke around with each other, and this teasing would occur almost exclusively in Farsi. Her father never joked in Farsi with her in the same way.

W1G2 also spoke Assyrian with her family, as it was one of her mother's native languages. The Persian classes at her university encouraged her to practice more Assyrian at home. When speaking of her Assyrian identity, as opposed to her Persian identity, W1G2 said the following:

l've been thinking about it a lot more these past couple of years.

I kind of feel guilty.

I feel more of an imperative.

It's kind of a complication to my identity. . . I do like it, I think it's positive, but at time l've been like - it just makes me not fit in even more. . . it's harder to intensely be a bunch of things.

Assyrian was W1G2's first language, because strictly speaking, she was introduced to it earlier than Persian. She became visibly emotional when talking about her Assyrian identity and language skills. Because the Assyrian people had no borders of their own and needed to carefully preserve what little is left of their language and culture, she felt compelled to take part in that preservation at the personal level. She was aware of its endangered status, but also aware of what it meant to her family, her mother in particular. Throughout the interview, whenever she mentioned Assyrian, W1G2 would apologize for mentioning a language other than Farsi. It was clear that Assyrian was incredibly meaningful to her, and held both linguistic and personal value. She expressed both a desire to enroll in Assyrian language classes, and recognized the difficulty of maintaining multiple languages and identities at once.

Outside of the family, W1G2 expressed gratitude for having family friends who also spoke Farsi: "We're a resource for each other." W1G2 described herself as having the weakest skills in Farsi out of everyone in her group of Persian friends. Thus, she enjoyed using her friends as a resource to improve her Farsi, taking cues and asking for guidance from more 
experienced speakers. This goal of speaking more fluently with her friends was a strong motivator to use her heritage language in her daily life. Now that she and her friends did not attend as many community gatherings as they did in childhood, she felt that these friendships were a good way to stay connected to the language. Spending time on campus was also a great way to practice speaking with friends, because they took Persian language classes together. W1G2 would speak both Farsi and English with her friends, but would usually speak English when "We're kind of talking in an American mindset." This introduces the idea that, when speaking, a speaker may have a multitude of triggers to switch into a particular language. For W1G2, this "American mindset" would be a trigger to use English with her friends, with whom she would normally use Farsi.

W2G2 had two younger siblings and a mother and father within her immediate family. She was in her early twenties, with her sister and brother being roughly five and six years her junior, respectively. Her parents came to the U.S. with student visas to study at the college level. Thus, they had been highly fluent in both of their family's languages for a long time, and so would converse with each other in both Farsi and in English, with no overt preferences. Whether they spoke to her in Farsi or English, W2G2 preferred to respond in Farsi. She had recently begun Persian language classes, and noted that her parents spoke even more Farsi with her than before in order to help her practice. She would use Farsi with her parents more consistently than her siblings, mostly because of her stronger command of Farsi compared to her younger sister and brother. Her brother in particular had learned less Farsi than either of his sisters, and although it appeared to his family that he understood spoken Farsi, his ability to reply was limited to a few words and short phrases. He replied to almost all family conversations exclusively in English, even when specifically prompted to switch to Farsi. When the three siblings were out and about, they would use simple phrases in Farsi to maintain privacy, but when at home or in a more private setting, they would exclusively use English.

With friends, W2G2 found it more fun to speak Farsi, and even used it where others 
might stick to English: "I was hanging out with some friends, and they're half Iranian, and one of them doesn't understand Farsi at all. But I found myself speaking Farsi to him, even though he didn't understand." This mismatch between interlocutor and language is interesting: W2G2 was using Persian friends as a domain that signaled using Farsi, despite the fact that this particular friend only speaks English. Her use of Farsi and English (with her friends that speak both) is similar to use with her siblings: when in public, Farsi is strongly preferred, but in a home environment, they would speak mainly English. W2G2 did warn that speaking so much Farsi in public places had gotten her into strange situations:

One time we were talking in Farsi about a guy that was standing behind us. We found out that he was actually Persian too and understood everything! So it's gotten us in trouble a couple times, but it's come in handy.

W2G2 used her heritage language among speakers that presumably speak only the dominant language, a tactic used for privacy. In this way, Farsi became a resource for her and her friends, allowing them to converse safely without worry of others eavesdropping, although it was not always foolproof. Like W1G2, W2G2 enjoyed practicing Farsi while on her college campus, as well as with family friends. Because she still had strong ties with some of her extended family, she used Farsi whenever she talked to them, especially because some members of her family were not that comfortable using English.

W1G1 immigrated to the United States with her mother after her older brother came over several years earlier. She left Iran as a teenager with her mother and siblings, and at the time of the interview, had been joined by cousins and other family members. Although she did not have children of her own, she spent time regularly with her nephews and cousins who were secondgeneration immigrants or more recent first-generation immigrants. She described her attempts to speak Farsi to two of her nephews: "It's awkward, you know. So they understand somewhat, but they always usually answer back in English." Here, W1G1 began to establish a pattern: whenever the interlocutor answered in English, either out of inability to respond in Farsi or out of 
choice, she became frustrated and switched to English during future interactions with that interlocutor. She discussed her language use with family members, feeling that she spoke mostly in Farsi to fellow first-generation immigrants such as her mother and brothers. However, she chose English for second-generation family members or anyone who struggled with Farsi. In her work life, W1G1 noticed that she did have some Persian clients, although it was uncommon. She would try her best to use Farsi with these clients but was surprised to find that English was more useful: "That's hard for me, to communicate in technical terms in Farsi... So explaining to them how to stretch and things is hard for me." Language in the workplace was not an important component of all interviews, but for W1G1, it was notable because she surprised herself whenever she could not find a translation for the English technical terms she had learned for her profession. Work-related jargon can tend to be more accessible to a speaker in the majority language, rather than in their heritage language. This kind of vocabulary is only rarely learned in a home environment, where the heritage language is most likely to be spoken.

Among her Persian friends, W1G1 reported speaking almost entirely in Farsi, with the exception of one friend her age who was born in the United States. "I have a Persian friend who was born here, so with her we speak English. Although she wants to learn more Farsi. But we speak English." As with her nephews, W1G1 displayed little patience with her friend who spoke less Farsi than W1G1 deemed necessary to avoid a switch to English. Regardless of whether she preferred to speak Farsi or English with this friend, keeping the conversation in Farsi was too much of a burden on W1G1's time and energy. Even though she regarded her own behavior of switching to English as negative and shameful, she admitted that she would rather use whatever is easiest given the context. When asked about her friend's level of fluency in Farsi, W1G1 elaborated: “She tries. But I'm not patient enough either, I don't think. I'm not a good teacher." This confirmed that she did not feel it was her duty to help any speaker of Farsi practice with her, but that they should be improving on their own time. 
Therefore, she preferred to just stay in English during conversations with this friend, whose lower language competency created a noticeable difference between her and W1G1's other Persian friends.

M1G1 met his wife in Iran. She is an American but also a fluent speaker of Farsi. They moved to the United States, and eventually to Portland, where they raised one daughter. The parents spoke mostly Farsi together, with English as a secondary language used only when needed. Their daughter was raised with both languages and was fluent in Farsi up until grade school when English became her dominant language. Interestingly, despite being exposed to a high volume of Farsi in her home life, school exerted a stronger pressure on M1G1's daughter than he or his wife were able to combat. Instead of trying to actively combat the language choices they noticed occurring with their daughter, they felt it was best to let her take the lead and make her own choices regarding what language(s) to speak.

M2G1 and his wife both spoke Farsi and English, and spoke almost exclusively Farsi with each other. They spoke both English and Farsi at their family-owned restaurant because several of their employees were Persian, as well as many of their customers. Their two sons understood Farsi when it was spoken to them, but they almost exclusively replied in English.

My kids, the good thing is that they understand it -- I used to drive around with my kids, and I say words in Farsi. Test them. And they knew it! . . They've heard it so much. They could speak it in the beginning, but unfortunately, never got to a point to fluently speak it.

Although he did not say it explicitly, here M2G1 was suggesting that there were factors more powerful influencing his sons' language choices than his efforts to explicitly instruct and practice with them in Farsi. It is likely that the school system, which exerts a strong pressure on children to conform and adopt English was in conflict with his fatherly language influence.

M2G1 felt that his wife is partially to blame for their children's heavy use of English, for he feels that he is a stronger advocate for Farsi than she is: "I am speaking Farsi to them, and I 
come home, and she is speaking English to them." Whether it was based in reality or just a perception, it is important to note that M2G1 felt undermined within his own family circle. He perceived himself, in relation to his wife, as a better parent as far as language maintenance was concerned: he felt that his wife did not value their heritage language to the extent that he did. Part of the reason that M2G1 feels that his sons developed English in favor of Farsi is the ways he and his wife raised them when they were younger:

Unfortunately I was working a lot, and she was involved in a lot of these playgroups with all these other moms, mainly non-Persians, you know? Some of her best friends are like Chinese, Americans, and they all speak English.

It is likely that his wife valued socializing as a mother, both for her own and her children's social needs, and was not as concerned about exposing her children to play environments where they would be exposed to Farsi in particular.

All four families exhibited language shift to varying degrees. For the two secondgeneration participants, both Farsi and English were reported as spoken in the home; Farsi was said to be more common when interacting with parents, while English was more common when speaking with siblings. Both W1G2 and W2G2 had trouble maintaining their heritage language during high school, but were now actively working to attain full competence in Farsi, including the written language. The Persian language program at Portland State University was credited for helping them to read and write in Persian as well as practice their speaking skills. Both participants reported that their parents had supplemented their classroom learning by increasing the amount of Farsi spoken with them in the home, even casually quizzing them on some elements of the language such as how to spell words they had learned in class. W1G2 reported that although her older brother's Farsi seemed to be at a higher level than her own, he was not as cognizant of his cultural identity and linguistic skills and would only speak English with her, either due to his personality or out of personal choice. W2G2, however, seemed to speak English with her siblings due to the younger brother's weaker skills in Farsi. 
The language shift seen in the first-generation participants' families was more severe, with the American school system undermining the second-generation children's use of Farsi, for they now speak almost entirely in English. M1G1 guessed that this is due to the lack of resources in the area for his daughter to retain Farsi throughout childhood, as well as her choices as an individual. He and his wife did not want their daughter to feel as if she was forced into speaking Farsi; nonetheless, he believed that as an adult she could return to speaking her heritage language of her own volition. M2G1 expressed hopes that his children may focus more on speaking Farsi as they enter adulthood, but also acknowledged that the only situations where they have a chance to use Farsi would be at home or with the extended family.

Interviews covered not only the participant's language use, but their language attitudes. The interviewees shared some of their beliefs about Farsi and English, as well as the relationship between language and culture. Some of this talk about attitudes was guided by interview questions, while some came from the interviewees themselves.

M1G1 felt strongly about Farsi not being a "pure" language, and spent a large portion of the interview explaining his attitudes toward Farsi in comparison to other languages. He felt that Farsi was corrupted because its speakers borrow so many words from other languages rather than relying on words that were etymologically Farsi. He would prefer that new Persian words be created rather than borrowed from another language. Additionally, he felt that these borrowings or "flaws" within Farsi made it more difficult to translate into English, or any other language for that matter. He felt that some areas of French and Arabic had taken over Farsi, and thus when Farsi is translated, the meanings, and even the sound of the language, can never be correctly conveyed. When asked whether he thought English was a pure language, M1G1 expressed frustration about English being also too strongly influenced by other languages, especially because of changes that occurred during the Viking invasions and the spread of the Catholic Church. These views on language change and borrowings are fairly 
conservative, as linguistics currently favors a more descriptive approach, disfavoring assigning values to a language such as "impure" or "corrupted" by words that are etymologically diverse. Given that M1G1's wife works closely with language, this was a surprising viewpoint for him to hold. Furthermore, it is possible that his views on the (lack of) purity of language could have influenced his decision to take a more hands-off approach with his daughter's language development throughout childhood.

M2G1 saw each language as a resource. He described how his cousin was raising his children, which he saw as ideal:

My cousin has two boys, a two-year-old and a 6-month...and the two-year-old, he starts speaking, and all he speaks to him is Farsi. Fortunately for them, they're not around a lot of English-speaking people, mainly Farsi. Their friends are Persians and the whole time they speak Farsi -- that's all he hears. And I told him, I said, that's great because he's gonna learn English no matter what. Once he starts school, I mean kindergarten or something, he doesn't wanna speak Farsi anymore.

It was fascinating to hear M2G1 present a concrete example to demonstrate what he would have rather had happen as he was raising his own sons. He described a childhood with only mandatory English influences present, such as school. He wished that his children had been more heavily exposed to Farsi throughout their childhood, which would likely have helped them retain it at a higher level. M2G1 wanted to pass down his heritage language so that his children could share Farsi with their family and each other. He felt that if his sons started to recognize the value of speaking multiple languages, they would practice Farsi more, and even start to learn more languages. He himself spoke German because he sought political asylum in Germany for several years, and his wife spoke French that she learned at elementary school in Morocco, and later while living in France with her mother. Although at the time of the interview, he and his wife did not practice German or French on a regular basis, they still used them on occasion and were thankful to be able to remember them after learning them several decades 
ago. He recounted a particular memory where speaking another language was meaningful:

The Greek restaurant I worked in in Vancouver, this older couple used to come in from Austria. Man. They would come on Thursdays, every Thursday! . . . They had such a good time just speaking, and this was when I spoke more, because I was more fresh. But yeah, it's great. It opens another world. It's a door to another culture, another world, basically.

Through this story, M2G1 revealed how highly he valued sharing languages with other speakers. Even languages above and beyond his first and second languages he considered to be of importance, allowing him to forge connections and establish personal relationships he could not otherwise. M2G1 also noticed the value of speaking Farsi in his professional life. Farsi had connected him over the years to countless connections in the food industry, including the period after he moved to Portland, Oregon.

Although she was a first-generation immigrant, W1G1 left Iran as a young teenager, and described a feeling of being neither fully a master of one language nor the other: "I feel like I don't know English a hundred percent, and I don't remember Farsi a hundred percent. So I'm stuck somewhere in the middle." This feeling of being a part of two worlds, linguistically and culturally, yet not fully a member of either, is common among immigrants.

Part of the reason for these feelings to be so strongly present in a first-generation immigrant is that W1G1 came to the United States as teenager. At the time of her travel out of Iran and through several holding states, she had not yet gained a complete comprehension of her first language. She spent her formative teenage years abroad and being surrounded by unfamiliar languages. At this point, she was old enough be reaching a high level of fluency in Farsi, but was not immersed long enough to have a completely solid memory of the language, as speaker who left Iran as an adult might. She felt guilty, nearly apologizing during the interview, about her status as a speaker of Farsi. "I feel more comfortable with English than I do 
with Farsi. It's sad."

Despite feelings of regret over her skills in Farsi, she did not want to practice and improve her language skills. Although she read Farsi sometimes, she would not consciously read as language practice. "I have some friends that love the poetry and stuff and I do too, I think the poetry is beautiful, but I see myself reading the English translations more than I do the Farsi when I do. It's horrible." Here W1G1 displayed a sense of guilt for not improving her Farsi, yet a contrasting behavior of not putting in the efforts necessary to improve her competency. This suggested that others may have pressured her or made her feel shameful about her "incomplete" grasp of Farsi. She herself did not express a desire to spend time speaking Farsi more than was practical during her conversations with other speakers. This shows a disparity between the inner beliefs that she felt were forced upon her and her everyday behavior. Even though W1G1 was aware that being more fluent in Farsi was viewed as favorable, she did not act upon this idea.

When asked why she did not attempt to increase her skills in Farsi, W1G1 described feelings of wanting to be uninvolved with Iran, a desire she had held since childhood: "I'm not very patriotic. Some of my friends are, they want to hold on to that. Since I was five, I wanted to get out of there. So when I did, I kind of left everything behind in a way." Ever since she was a child, W1G1 had admired American culture and considered it more valuable than the Iranian culture. Throughout her life, American culture excited her, and she felt positively towards it even as an adult. Once she moved to Oregon, she felt that she assimilated quickly and easily adapted her lifestyle to fit the culture.

When I was really little, my oldest brother moved here. I was probably four or five when he moved here, and I always looked up to him so much, and he was like my hero, and I always wanted to be here with him. And the kids like, when we were playing at home, I used to talk about him and America so much... And I used to wear a cowboy hat or like a marshal's badge. So I always had this fascination with America, and I just adapted 
really fast to the culture.

Interestingly, W1G1 felt that any instances of negative cultural pressures she had experienced came from the Iranian culture, and not from the American culture exerting pressure to conform. In contrast to her negative at times jarring memories of Iran, W1G1 was able to create strong positive associations with the American culture, and by extension, the English language. These attitudes towards culture could provide insight into why language shift can occur within the first generation.

W2G2 and her family lived in Seattle until she was five or six years old, and spoke only Farsi until preschool at age four. She shared how this upbringing caused her to defend her identity: "I've gotten it so much as a child, like 'Oh, you're brown. Where are you from?' I'm like 'Seattle. Sorry to disappoint!' And they'd be like 'No, your ethnicity." This example showed an instance of W2G2 attempting to dissuade white Americans from stereotyping her. As a child, she was already aware of the labels that other children were trying to assign her, and she did not want others to assign her to a different box than more stereotypical "American" looking children. This contributed to her hesitation to reveal the Iranian part of her identity.

Another factor that contributed to the way W2G2 was seen by other children was that she was raised by her grandmother because both of her parents worked when she was little. Therefore, she had to learn English primarily through the school system. "Growing up, I would have to take ESL classes. And they would ask, 'Why are you in ESL? Are you from here?' And I'm like 'No. Well yeah I am, but didn't learn English first."' As a child growing up in Seattle but speaking mostly Farsi, W2G2 did not see any problem with her upbringing, and she considered it normal. It was not until she started school that she discovered that many other children had a different idea of what a "normal" home life looked life. W2G2 expressed how high school was an important time in her life, highlighting how pressures from society had warped her view of herself. Generally, she expressed pride and excitement over her connections to the Persian culture and her ability to speak multiple languages. However, this had not always been the 
case, "Growing up, it was always something I wanted to suppress."

W2G2 went to a private high school where her classmates and other people at her school, even teachers, would comment on her ethnicity and criticize her when she acted in a way that was deemed by others to not be "normal" and "American." She tried to ignore their comments, but she also did not want to be excluded or seen as different. "Speaking Farsi and being Iranian was only something that came out when I was around people I was comfortable with. . . I couldn't embrace it until I left [high school]."

As a way to cope with bullying and being seen as different from her classmates at her small private school, M2G2 felt that the best solution was to repress her Iranian identity when in public. This was carried out, in part, by not letting herself be heard speaking Farsi: she did not want to be differentiated from other English-speaking teenagers. Outside of the home, she began to speak only English, reserving Farsi for family and close family friends: "When I left the house it was just like, no, I'm an American, and I am, born and raised. Therefore, I'm not going to accept the Iranian stamp on me." Along with hiding the Iranian parts of her identity in public, W2G2 began to internally reject that side of herself, hoping to become an average American in order to have a successful social life. The turning point in her life was the beginning of college. Once she left high school behind, she began to see her bilingualism as a gift and a resource, and she enrolled in classes to improve her Persian reading and writing skills. At the time of the interview, she felt that her language and culture were valuable to her identity and worth expressing to others.

Informants were asked whether they prefer the term 'Iranian' or 'Persian' when referring to their own identity, and most responses were fairly neutral. M2G2, however, preferred the term Persian. "If you say Iranian, they'll be like 'Oh, from Iraq." When asked how she handles continued negative comments now that she is an adult, she replied, "You just learn to embrace the questions and the assumptions, and you just inform and correct -- as much as you can." However, W2G2 was now prepared to stand up to bullies and not let her adulthood mirror her 
childhood experiences.

At this point in my life, the more ignorant comments that I get, I'm just like, 'Well, you don't know any better because of the society we're in right now. You don't know any better because of the influence that you see right now in every aspect of society.' So it's like, I just see you as an ignorant ho.

W2G2 was now confident in all intersections of her identity, and would no longer let ignorant onlookers influence who she saw herself as, including what languages she decided to speak.

W1G2 did not seem to let the pressures of society get to her. "I can think of moments when I was younger where I was like, 'Oh, I'm embarrassed that my parents have an accent.'” Overall, W1G2 did not see herself as different from other children. The exception was certain moments when she compared her parents to other parents, and realized that the language she was exposed to was different than what would be considered the norm. But if someone did not want to accept her identity, she did not have any patience with them. She described feelings of isolation at times, due to growing up in the Portland area: "I live in a place that is pretty white and without many people with multiple identities. If I lived in like New York it would be completely normal." Although at the time of the interview, Portland was still growing in size, it did remain relatively white in comparison to other larger cities, particularly in regards to the gentrification and lack of particular resources for different cultural groups. This comparison with other cities caused W1G2 to feel some discontent with her identity, because she felt like she did not have many other people around her who were experiencing the same struggles with linguistic and cultural plurality. Throughout her life, W1G2 tried to not let American cultural ideas seep into her view of herself to the point that she changed for someone else.

The idea that there is only one way to be an American has affected me, but more in the sense that I have to know how to be many different things. And I have to be able to anticipate what white America wants from me, and then go from there. 
W1G2 was alluding here to the current political climate in the United States, which had sharpened her awareness of how she could be seen as an outsider when judged by more privileged Americans. Although she saw herself as fully American, she recognized that given recent political events, some could be emboldened to voice their prejudices against her.

Like W2G2, W1G2 attended a high school that was primarily composed of white, uppermiddle class Protestants. During this period in her life, it was difficult for her to claim her identity as a Persian. "Obviously the white Evangelical church is one of the most racist places you can be ... it's very pronounced, and specific." Because she attended a private, Christian school, she recognized that the typical teenage phase of changing oneself for the approval of others was exacerbated. Even more than at a typical high school, teachers and classmates, even the principal of the school himself, made racist remarks.

W1G2 felt that her connections to her heritage language and her heritage culture were valuable, but that they were in some ways a means to an end. She saw her identity as being up to chance, that she randomly was born into the life she leads. However, she felt lucky to be in a family where multiple languages can flourish:

Even just knowing different languages, it's helped like deepen certain parts of me, and helped me understand complexity and not take certain things for granted as far as assuming things . . . even if you forget it, it's there. It's always there.

W1G2 observed that she was introspective and probably more sensitive than others in the same situation. This allowed her to reveal how she believed that language could be an asset to the development of her personality and understanding of the world. W1G2's connections to her language and culture were largely due to personal interests. After high school, her interest in Persian poetry, literature, and film increased. Through poetry, she gained insight into Iranian life and felt able to explore the values of her heritage culture. Some of the media that W1G2 sought out was available in Farsi but written out in the Latin alphabet. This encouraged her to practice her heritage language, as her spoken skills were much stronger than her reading and writing 
abilities. Interestingly, W1G2 felt that her cultural and linguistic identities were somewhat disconnected. She noted that even a Persian-American who spoke mostly English would still have the ability to be immersed in the culture and claim it as a strong part of their identity. From her perspective the language element of her identity was controlled by her personal choices and not dictated by the pressures around her.

Another topic covered in interviews was the resources and technologies that participants and their families found helpful or lacking for maintaining Farsi. M1G1 expressed that no amount of resources could really make up for the strong pressure that the American school system exerted on his daughter. He found that her school and the Portland community did not offer any resources for her to maintain her Farsi skills, which faded quickly as her time in school increased. He also noted that this pressure still would have been quite strong had he and his wife tried to homeschool their daughter. M1G1 recognized not only that the linguistic pressures of school system were too powerful to overcome, but also that the underlying pressure came from the infrastructure of American society, not just public school alone. He felt that there was no way to shelter his daughter from English to the extent that she would still rely on Farsi for communication.

M2G1 noted that he and his family, including his extended family, enjoyed speaking Farsi with each other, but that they all tended to text each other in English. Because he and his family got used to using cellphone keyboards with the Latin alphabet, it was cumbersome to use the Persian script on their phones. He would find himself replying too slowly to texts, and even emails, if he used Farsi instead of English. Thus, the modality of cellphones saw the most language shift to English and was the exception to the general rule of the language use in his family. M2G1 also noted that there were several community resources that his family could have taken advantage of:

There are a few other - there's like a Persian cultural community and stuff like that. My friends do stuff like that, they might all go on a picnic. In August, there's a . . Persian 
festival or something like that, every year.

Despite his interest in passing on the Persian culture and language to his sons, he noted that he and his family did not have enough free time to find Persian events or Persian language practice in the Portland area. What limited time they had was spent running their business or relaxing together as a family. The time constraints of everyday life conflicting with his desire to have his sons be involved with their heritage language was a painful reality for M2G1. Although he hoped that more involvement with the local Persian community would be beneficial to his sons by giving them another way to be exposed to Farsi, he admitted that his own work schedule as well as his family's lifestyle could not accommodate the extra time and energy it would take to attend these events regularly.

W1G1 communicated with cousins that more recently moved to Portland by typing with her Persian keyboard. These cousins who moved from Iran more recently had begun learning English, but still had a much better command of Farsi. However, W1G1 did not enjoy using the Persian keyboard to communicate:

I have couple cousins that just moved here, so I do use it with them. But I hate it. I just do it because they have a hard time. I'm like, 'You guys need to learn English!'... I feel like, you're in a country, you need to adapt. And learn the ways.

Here, W1G1 showed that she not only believes that she herself should use English as much as possible, but that other Persians need to as well, in order to call themselves Americans. She did not share this viewpoint aloud with her cousins, but kept thinking it whenever she interacted with them, distressed they were not doing more to assimilate linguistically.

Other than with her cousins, W1G1 used most technologies such as her phone and the Internet exclusively in English. She participated in several annual community events for the Persian community in Portland, but had become more unwilling. "I only go if I really have to. My mom loves to go, so she makes me sometimes. I just don't feel like it anymore." Out of obligation to her mother, W1G1 still went occasionally to Persian-themed events in Portland. At 
the time of the interview, they had not been to an event together since Persian new year of the previous year. When asked what the events were like, she described how it felt for her to attend: The people that were there were so annoying! It made me not want to go back there. They were all very young, and they're very new. And I just didn't feel comfortable, you know. A lot of Persians moved here recently, through the UN, I think. Through the refugee thing. There are a lot of young ones, and I don't even understand their lingo anymore, slang Persian.

Even though she feels that the events for the Persian community are not purposefully aimed at younger Persians, there are more in attendance than immigrants who came over earlier. W1G1 confirmed that she will no longer go to these events in the future. "Why should I go if I don't enjoy it or relate to it." It was interesting to hear that W1G1 felt more comfortable within the Portland community among non-Iranians than at events that specifically were targeted at the Persian population of Portland.

W2G2 found that because her father had Microsoft Word in Farsi, as well as Persian alphabet stickers on her family's computer keyboard, she was motivated to learn how to type in Farsi. One of her goals was to eventually read and write more Farsi online, and to be able to type more quickly as a way of honing her language skills. W2G2 made phone calls mostly in English, but she and her family members would sometimes explicitly switch to Farsi over the phone by saying "respond in Farsi" so that the rest of the phone call could not be easily overheard. When texting, she would similarly text in English, but sometimes in transliterated Farsi so people could not read over her shoulder.

W1G2 used social media primarily in English, as well as texting. When texting with her parents, she would accommodate their English language idiosyncrasies by mimicking their incorrect subject-verb agreement or omission of articles. This style of English became so common that, especially with her mother, W1G2 would speak this way with her family in person as well. Unlike texting however, W1G2 would place phone calls in Farsi as much as she could, 
just to retain the privacy of the call. She praised Spotify and other online music resources for providing her with access to a wide range of Persian music, particularly traditional folk music. She strengthened her vocabulary in Farsi by looking up transliterations of the lyrics online. Her parents were surprised that she found Iranian folk music on her own with the help of the internet, rather than with their assistance. Not only did she feel that Iranian music helped her practice listening in the language, but along with Persian poetry, it gave her a sense of a deep connection with her Persian identity. She felt that music and poetry were incredibly valuable in giving her linguistic and cultural insight into Iran and the history and values of her community. Her language practice through poetry and song strengthened her cultural understanding even more than her language skills: "In the same way that the Internet has expanded worlds and minds, it has made me more interested in my own culture."

Both second-generation participants were asked about their predictions for the next generation of Persian-Americans in Portland. W2G2 expressed pride in her language and culture:

It's a really good culture to be a part of. It's really fun and it's really exciting and I think I would want my child to at least see, even if they can't speak it, and they later on want to be a part of it.

It was clear that W2G2 loved and took pride in her Persian heritage to the point that she felt she would be likely to raise her children with Farsi and other elements of culture from Iran. She noted that her potential children would spend large amounts of time around her family, such that it would only be a natural consequence for them to grow up hearing Farsi and learning about Iran. She communicated a desire for any future children of hers be involved in the Iranian community and immersed in the culture. She would be okay with her child not knowing how to respond to conversations in Farsi, as long as they could understand and be exposed to it.

W1G2's brother, at the time of interviews, was just becoming a parent to his first son, together with his English-speaking wife. W1G2 recognized that her parents were taking an 
interest in passing down the Persian language and culture to their newborn grandson, which she found to be surprising, considering how she herself was raised: "My parents aren't the type of people like, 'Oh, don't you want to preserve the culture?' They don't have that attitude." Her father in particular kept saying that he will speak in Farsi to the baby so it will surely know it when he grows up. It is possible that W1G2's father had focused earlier on integrating his family into American society, and so had not consciously given his children any extra practice with the language. Now that they his family was firmly rooted in both cultures, he could allow himself to focus on introducing his grandchild to Farsi again and sharing Iranian culture with him. Both parents of the baby boy, according to W1G2, were going to prioritize the religious upbringing of the child over his linguistic upbringing, and would thus be likely to teach him mostly English.

When speaking of her own hypothetical children, she took a realistic approach: "I want to try [to teach them Farsi], but it would be hard without concentrated effort." She expressed little hope for future generations in Portland, Oregon, feeling that over time, the Persian language and culture will die out outside of Iran. "If I lived in California though, where there are so many Iranians -- maybe that would be different." She discussed the effects of moving and raising a family in a larger city on her future children's languages, but noted that it would not be a priority for her personally. "A lot of our friends ended up moving to California for that reason. It's a lot easier in all kinds of ways. Occupationally, communally, you know. It's nice to have that camaraderie, and there just aren't the Persians here."

As evidenced by the participant responses detailed above, language shift among Persians was occurring in Portland. The city was not large enough, nor provided the right kind of resources, for the community itself to be sustained longer than the typical three-generation lifespan of bilingualism. However, individuals tried to consciously maintain Farsi for various reasons, including pride for their culture and enjoyment of Iranian poetry and song. Farsi was most often spoken around family, with some families where second-generation children responded to parents in English, and others where the children would try to reply in Farsi when 
possible. All families experienced a lack of Farsi spoken between siblings, except for occasional words or short phrases. Overall, the oldest sibling would receive more Farsi from their parents, whereas younger siblings would be progressively addressed using more English. With family friends and extended family members, most respondents did rely on Farsi to communicate. Several families revealed successfully that integrating into American society was a priority in their lives, placed above the desire to pass on the heritage language.

This struggle to be successful in American society, especially in school, motivated language shift in participants. The second-generation participants, however, found themselves returning to Farsi after their school years had passed. Their excitement with their culture, or particular elements of their culture, motivated them to reconnect with their heritage, including practicing more Farsi. They both enrolled in Persian courses at Portland State University to improve their reading and writing skills. However, the first-generation participants provided a bleaker outlook on language maintenance, because all reported experiences of younger family members using almost exclusively English. It is interesting to note that whether the secondgeneration Persian-Americans are retaining Farsi or not is disagreed upon, and that this disagreement falls along generational lines. This suggests that the first generation's observations of the second generation is different from the second generation's perspective on themselves. Finally, participants' predictions for the future were that even though individual parents or older relatives may attempt to educate the upcoming third generation on Iranian culture and help them learn Persian, there will be an imbalance between the connections these children will feel to their American versus Iranian roots. Farsi will eventually fall out of use in Portland: although some parents may have ideals of raising the next generation with knowledge of Farsi, the infrastructure of Portland does not help support this goal.

\section{Conclusion}

Minority immigrant communities, such as the Persian diaspora in the United States, can 
benefit from ethnographic research that provides insight into the cultural and linguistic realities that individual immigrants face. This study has attempted to do just that, as well as contribute to the existing research on language shift in Farsi. First, I introduced the topic of language shift and language maintenance, and situated these phenomena within the context of the United States. Then I provided an overview of previous scholarship on language shift in Farsi speakers, focusing on the work of Shiraz Felling (2006), who inspired this study. Previous work motivated the research questions that focused my work on Farsi in Portland, Oregon, as well as the methodology leading to the five informal interviews. I then reported the results of these interviews and finally, discussed how these interviews were connected to each other, my research questions, and the larger topic of language shift.

To bring my research full circle, I will now answer my research questions. The status of Farsi in Portland, Oregon seems to be best determined by the individual speaker. In some participants, language shift was fully operating, with shift evident in the first generation. However, in other participants, an active maintenance of Farsi language skills was present. Most participants speak Farsi in the home, especially with parents. Participants also reported speaking Farsi with close friends who were also Iranian-Americans. First-generation participants spoke Farsi with their siblings, but second-generation speakers switched to English, almost exclusively. Some individuals felt that they were pressured into behaving certain ways while in public, or during times in their life of intense peer pressure, such as high school. This societal pressure was described as affecting participants' thoughts on their own cultural identities, but as not necessarily as direct motivation behind language use. Most participants reported making language choices based on their attitude towards their Iranian roots -- pride in their heritage or fascination with music and poetry motivated several participants to strengthen their use of Farsi, whereas rejection of the Iranian culture caused one participant to prefer English. This was also how participants demonstrated how they connected their cultural identity and their language 
use. The connections were not necessarily revealed out loud, but they did motivate participants' behavior.

Participants felt that resources for Persians in the Portland area were not relevant to their needs, or that they did not have time to be involved in community events. However, technology such as online translations of poems or keyboards using Farsi script were mentioned as valuable and interesting aids to improving language skills. Finally, participants' predictions for the future of Farsi were that the inevitable influence of English would be too strong for the third generation, if living in Portland, to retain a balanced bilingualism. Future generations would need to move to another city in the United States with concentrated Iranian populations in order to be exposed to both English and Farsi in high quantities.

Even with a small sample size, it was hard to pinpoint what exactly guides language choice in the Persian diaspora. The Persian-American community, even in a smaller city such as Portland, is not monolithic. Some participants gave perspectives on their language and culture that were in opposition, and patterns were nearly impossible to generate. There are many voices to be heard when doing research in this field, and to simplify them down to one would risk misrepresenting the lived realities of each individual. The linguistic situation of FarsiEnglish bilinguals is more complex than I can properly characterize here, and I would not want to force my participants into simplifying themselves and providing anything but their complicated, intersectional experiences.

One important finding was the return to Farsi shown by two second-generation participants. Although their childhood and teenage years were full of exposure to English and peer pressure to be "normal Americans," the college years presented a time for maturity and self-reflection, where speakers were more conscious of the value of their heritage language and culture. This internal motivation worked in conjunction with a heritage language program provided by Portland State University that gave participants the support they needed to carry out their desire to strengthen and maintain Farsi, especially reading and writing. Because first- 
generation participants reported the heavy use of English in second-generation speakers, but these were speakers that had mostly not reached this young adult age, it is possible that they, too, may turn to Farsi as they grow older and become more established in their identities. Thus, longitudinal studies can be recommended to better track the fluctuation of Farsi fluency as participants in the second and third generations grow older.

Future research should look at what other factors influence individual speakers to retain or abandon their heritage language. Although macro data such as census figures should by no means be barred from future scholarship in language shift, the inclusion of perspectives at the personal level draws out a deeper understanding of the different linguistic and cultural situations each immigrant experiences. Research may benefit from including both first- and secondgeneration participants for a full picture. Although Felling's dissertation is expansive and thorough in considering the first generation of Iranian-American immigrants (Felling, 2006), her study, as well as the majority of the literature on this topic, do not provide data from both generations. The current study thus provides a unique and valuable way to approach research on language shift.

The relevance of heritage language programs for language maintenance is clear. Several participants in this study improved their language skills through the Persian language program at Portland State University, an experience that would have been difficult to replicate without such support. If universities and cities retain current funding and begin increasing access to heritage language programs, immigrant communities may have a better chance at being connected to the languages that they cherish and value, no matter the motivation. Extending the lifespan of heritage languages beyond the third generation is still a difficult feat, but this challenge can be faced by providing resources to communities that preserve their heritage languages. After all, supporting the language maintenance of individual speakers is the key to whether each immigrant community preserves or loses their heritage language. 


\section{References}

Babaee, N. (2013). Reminiscing about childhood: The language maintenance of an Iranian in the United Kingdom. Diaspora, Indigenous, and Minority Education, 7(4), 199-213.

Bozorgmehr, M. (1998). From Iranian studies to studies of Iranians in the United States. Iranian Studies, 31(1), 4-30.

Crawford, J. (1992). Hold your tongue: Bilingualism and the politics of "English Only." Reading, MA: Addison-Wesley Publishing Company.

Felling, S. Fading farsi: Language policy, ideology, and shift in the iranian american family.

Mahdi, A. A. (1998). Ethnic identity among second- generation Iranians in the United States.

Iranian Studies, 31(1), 77-95.

Namei, S. (2008). Language choice among Iranians in Sweden. Journal of Multilingual and Multicultural Development, 29(5), 419-437.

Romaine, S. (2000). Language in society: An introduction to sociolinguistics (2nd ed.). New York: Oxford University Press.

Shin, S. J. (2002). Birth order and the language experience of bilingual children. TESOL Quarterly, 36, 103-113.

Shirazi, R. (2014). The pedagogy of visibility: Constructs and contests of Iranianness in a community organized school in a large southern U.S. city. Diaspora, Indigenous, and Minority Education, 8(2), 108-124.

Spradley, J. P. (1979). The ethnographic interview. Fort Worth, TX: Holt, Rinehart, and Winston, Inc.

Tse, L. (2001a). Resisting and reversing language shift: Heritage-language resilience among U.S. native biliterates. Harvard Educational Review, 71, 676-708. 
Tse, L. (2001b). Why don't they learn English? Separating fact from fallacy in the U.S. language debate. New York: Teachers College Press. 


\section{Appendix A}

Participant Reference Sheet

Below are the codes that reference each participant, along with a short description of each participant's basic characteristics as it pertains to this study.

M1G1 is a man who is a first-generation immigrant. He is married to a non-Iranian American woman who is a fluent speaker of Farsi. He and his wife speak mostly Farsi together in the home, but also speak English when needed. He has one daughter, who is now in her twenties. His daughter speaks almost entirely English.

M2G1 is a man who is a first-generation immigrant. He is married to an Iranian woman, and together they have two sons who are nineteen and seventeen years old. With his wife, he speaks Farsi the majority of the time. Although his sons understand Farsi, they reply to their parents in English and only speak English with each other.

W1G1 is a woman who is a first-generation immigrant. She came to the United States at the same time as her mother, and also has brothers and extended family in Portland. She has two nephews who are about seventeen and nineteen years old. She speaks Farsi with family members who are also first-generation immigrants, or can speak Farsi fluently. With secondgeneration immigrants or more inexperienced speakers, she switches to English.

W1G2 is a woman who is a second-generation immigrant. Her father speaks Farsi natively and also knows Assyrian and English at a high fluency. Her mother is a native speaker of Assyrian and Farsi, and speaks English as well, although not as fluently as the father. W1G2 has an older brother in his thirties who recently married a non-Iranian woman. They have a newborn 
baby boy. With her parents, W1G2 speaks both English and Farsi, but in the past few years, the ratio of Farsi to English has increased. Her brother speaks only English with her.

W2G2 is a woman who is a second-generation immigrant. Her mother and father speak Farsi natively, and also have a strong command of English. She has two younger siblings who are about nineteen and twenty years old. She speaks Farsi with her parents, as well as some English. Since entering college, she has spoken less English with them. With her younger sister, she speaks mostly English with some Farsi, but she speaks only English with her younger brother. 


\section{Appendix B}

Informal Interview Guideline Questions

(More questions arose depending on the experiences and personal interests of the participants.)

1. How would you describe how you learned Farsi and how you learned English?

2. How are Farsi and English used in your family?

3. What about in your extended family?

4. In community settings such as church or sports, do you notice any preferences for either language?

5. For first-generation participants: In work and professional environments, do you have a preference for using a particular language?

6. For second-generation participants: At your current/previous university and other schools, do you use Farsi in, or outside of, the classroom?

7. With friends and when you are just relaxing, would you say you use Farsi, English, or both?

8. Do you have any particular feelings or opinions about Farsi or English and how you use them or witness them being used by others in your community?

9. Are there resources or technologies available for you to practice Farsi here in Portland?

10. Does your identity and your language use feel like more of a choice, or more like a pressure you experience? How so? 